\title{
Influences of dietary methionine and cysteine on metabolic responses to immunological stress by Escherichia coli lipopolysaccharide injection, and mitogenic response in broiler chickens
}

\author{
BY K. TAKAHASHI, N. OHTA AND Y. AKIBA \\ Department of Animal Science, Faculty of Agriculture, Tohoku University, Sendai-shi, 981 Japan
}

(Received 14 January 1997 - Revised 2 April 1997 - Accepted 7 May 1997)

\begin{abstract}
The present experiments were conducted to investigate influences of dietary methionine and cysteine on metabolic responses to immunological stress induced by Escherichia coli lipopolysaccharide (LPS) injection, and concanavalin A (Con A)-induced mononuclear cell (MNC) proliferation in male broiler chickens. In Expt 1, chicks (12 d of age) were fed on a $S$ amino acid (SAA)-deficient diet $(5.6 \mathrm{~g} \mathrm{SAA} / \mathrm{kg}$ diet) or on three kinds of SAA-sufficient diet $(9.3 \mathrm{~g} \mathrm{SAA} / \mathrm{kg}$ diet; low-, medium- and high-cysteine diets) which contained $2.8,4.65$ and $6.5 \mathrm{~g}$ cysteine/kg diet, respectively. Plasma $\alpha-1$ acid glycoprotein (AGP) concentration and interleukin (IL)-1-like activity in chicks fed on the SAAdeficient diet were lower following a single injection of LPS than those in chicks fed on the SAAsufficient diets. At $16 \mathrm{~h}$ after LPS injection, plasma Fe and $\mathrm{Zn}$ concentrations and body weight were reduced, but AGP concentration and IL-1-like activity in plasma were significantly increased. These changes in body weight, plasma $\mathrm{Zn}$ and Fe concentrations following injection of LPS were not affected by dietary methionine:cysteine ratios. Plasma AGP concentration and $\mathrm{IL}$-1-like activity in chicks fed on the high-cysteine diet were, however, greater than those in chicks fed on the other diets following a single injection of LPS. In Expt 2, chicks ( $7 \mathrm{~d}$ of age) were fed on the SAA-sufficient diets as in Expt 1 for $10 \mathrm{~d}$. MNC proliferation in spleen induced by Con $A$ in chicks fed on the highcysteine diet was greater than that in chicks fed on the low- or medium-cysteine diet. The results suggest that dietary cysteine has an impact on the immune and inflammatory responses.
\end{abstract}

Methionine: Cysteine: Acute-phase response: Lipopolysaccharide

Dietary amino acids modify the metabolic changes that follow an immune response during inflammation. Grimble et al. (1992) indicated that cysteine, a S amino acid (SAA), is of prime importance in facilitating increases in liver GSH, $\mathrm{Zn}$ and protein content in rats treated with tumour necrosis factor (TNF)- $\alpha$. In chickens, the influence of the metabolic changes on certain amino acid requirements, e.g. SAA and lysine, under stressful conditions has been partially characterized. Chicks fed on a methionine-sufficient diet had higher interleukin-1 (IL-1) activity, growth rate and feed intake compared with chicks fed on a methionine-deficient diet when they received immunogen injections (Klasing \& Barnes, 1988). In mice, dietary methionine deficiency reduced mitogen-induced proliferation of $T$ cells (Nauss et. al. 1982). Tsiagbe et al. (1987b) showed that antibody production against sheep erythrocytes and delayed hypersensitivity against phytohaemagglutinin (PHA)-P in chicks fed on a SAA-deficient diet were lower than those in chicks fed on a SAA-sufficient diet.

Although Hunter \& Grimble (1994) showed that production of several acute-phase proteins in rats fed on a methionine-rich diet did not differ from that in rats fed on a 
cysteine-rich diet when they were injected with TNF- $\alpha$, it is likely that the role of cysteine in protection against stressful conditions is different from that of methionine. Tsiagbe $e$ al . (1987a) showed that cysteine was $70-84 \%$ as efficient as methionine in enhancing immunoglobulin-G (Ig-G) production and in delaying hypersensitivity to PHA-P stimulation respectively, indicating that cysteine is an important nutrient for the immune response in broilers. Feeding L-cysteine increases tissue GSH level. Increasing tissue GSH may be beneficial for growth of chicks reared in conditions of oxidative stress. Furthermore, cysteine and cysteine derivatives have been shown to modulate lymphocyte and macrophage functions in in vitro studies (Droge et al. 1991).

The purpose of the present study was to determine whether changes in the cysteine:methionine ratio within the SAA requirement recommended by the feeding standard (National Research Council, 1984) influence metabolic response following Escherichia coli lipopolysaccharide (LPS) injection and concanavalin A (Con A)-induced proliferation of splenocytes and thymocytes in broiler chickens.

\section{MATERIALS AND METHODS}

\section{Expt 1}

Male broiler chicks were housed in a battery brooder with an electric heater and fed on a commercial broiler starter diet until $12 \mathrm{~d}$ of age when sixty four chickens of most uniform body weight were selected from a total of ninety-six birds. They were randomly assigned to four groups of sixteen, with eight pairs of chicks in a cage.

The chicks were fed ad libitum for $14 \mathrm{~d}$ on either a SAA-deficient diet $(5.6 \mathrm{~g} \mathrm{SAA} / \mathrm{kg}$ diet) or three kinds of SAA-sufficient diet which contained an additional $3.7 \mathrm{~g}$ of either methionine or cysteine or equal quantities of methionine and cysteine on a weight basis (giving a total in each case of $9.3 \mathrm{~g} \mathrm{SAA} / \mathrm{kg}$ diet, as recommended by the National Research Council (1984) feeding standard). The basal diet consisted of $563.8 \mathrm{~g}$ maize, $255.2 \mathrm{~g}$ soyabean meal, $350 \mathrm{~g}$ soyabean protein, $51.0 \mathrm{~g}$ soyabean oil, $18.0 \mathrm{~g} \mathrm{Ca}_{3}\left(\mathrm{PO}_{4}\right)_{2}$, $12.3 \mathrm{~g} \mathrm{CaCO}_{3}, 2.9 \mathrm{~g} \mathrm{NaCl}, 1.5 \mathrm{~g} \mathrm{~L}$-lysine, $0.8 \mathrm{~g}$ L-threonine, $1.4 \mathrm{~g}$ L-arginine, $4.65 \mathrm{~g} \mathrm{~L}$ glutamic acid and $4 \mathrm{~g}$ mineral and vitamin mixture per $\mathrm{kg}$ diet. In the SAA-sufficient diets, $3.7 \mathrm{~g}$ glutamic acid in the basal diet was replaced with L-methionine, L-cysteine, or equal quantities of the two amino acids on a weight basis. Calculated metabolizable energy and crude protein contents of the experimental diets were $13.4 \mathrm{MJ}$ and $220 \mathrm{~g} / \mathrm{kg}$ diet respectively. Water was provided ad libitum.

At $26 \mathrm{~d}$ of age, eight chicks of each dietary group were injected intraperitoneally with $900 \mu \mathrm{g}$ of LPS and the remaining eight chicks were injected with sterilized saline $(9 \mathrm{~g}$ $\mathrm{NaCl} / \mathrm{l})$. Blood was obtained $16 \mathrm{~h}$ after the injections, and plasma was prepared. The diets were withdrawn after the LPS or saline injection. Body weight was measured before and after the injection.

Determination of IL-1-like activity in plasma was as described previously (Takahashi et al. 1995). The methods of determination of $\alpha-1$ acid glycoprotein (AGP), Fe and $\mathrm{Zn}$ concentrations in plasma were also as described in our previous reports (Takahashi et al. 1994, 1995).

\section{Expt 2}

In Expt 2, chicks (7 $\mathrm{d}$ of age) were divided into three groups of six chicks and fed ad libitum on the SAA-sufficient diets used in Expt 1. At $10 \mathrm{~d}$ after giving the diets, four chicks were randomly selected from each dietary group to determine the Con A-induced 
proliferative response of mononuclear cells (MNC) of spleen and thymus. Preparation of MNC and determination of the proliferation were as described elsewhere (Takahashi \& Akiba, 1996). A stimulation index was used to assess the proliferative response of $\mathrm{MNC}$ in the spleen and thymus. The stimulation index is the ratio between incorporation of $\left[{ }^{3} \mathrm{H}\right]-$ thymidine into MNC stimulated by Con A to that unstimulated by Con A.

\section{Statistical analysis}

A 4 (dietary treatments) $\times 2$ (the injection procedure, the LPS and saline injections) factorial statistical test was applied to analyse the data in Expt 1 and the calculation was carried out using the general linear model of Statistical Analysis Systems, 1982 version (SAS Institute, Cary, NC, USA). The data in Expt 2 and part of Expt 1 were analysed by the general linear model of Statistical Analysis Systems with Duncan's multiple-range test.

\section{RESULTS}

Table 1 shows final body weight at $26 \mathrm{~d}$ of age and feed intake for days 14-26 of age. Body weight and feed intake were significantly lower in chicks fed on the SAA-deficient diet than in chicks fed on the SAA-sufficient diets. No significant changes in body weight and feed intake were apparent among chicks fed on the SAA-sufficient diets for this period.

Table 2 shows the influence of dietary methionine and cysteine on body weight changes, Fe, $\mathrm{Zn}$ and AGP concentrations and IL-1-like activity in plasma in chicks after the LPS or saline injection. LPS injection resulted in reductions of body weight (except for the low cysteine diet), plasma Fe and Zn, but in increases in plasma AGP and IL-1-like activity as compared with the control group. The increase in plasma AGP concentration following LPS injection was greater in chicks fed on the three SAA-sufficient diets as compared with that in chicks fed on the SAA-deficient diet. Plasma IL-1-like activity following LPS injection in chicks fed on the high-cysteine diet was greater than that in chicks fed on the other diets.

Table 3 shows the influence of dietary methionine and cysteine on the Con A-induced proliferative response of MNC in spleen and thymus. The response in spleen MNC was

Table 1. Expt 1. Influence of dietary methionine and cysteine on body weight at 26 d of age* and feed intake from 12 to 26 d of age in broiler chickens fed on diets deficient or sufficient in sulfur amino acids (SAA)†

(Mean values with their standard errors)

\begin{tabular}{|c|c|c|c|c|c|c|}
\hline \multirow[b]{2}{*}{ Diet } & \multicolumn{2}{|c|}{$\begin{array}{c}\text { Met or Cys added } \\
\text { to SAA-deficient diet } \\
(\mathrm{g} / \mathrm{kg})\end{array}$} & \multicolumn{2}{|c|}{$\begin{array}{l}\text { Body wt }(\mathrm{g}) \\
\quad(n \text { 16) }\end{array}$} & \multicolumn{2}{|c|}{$\begin{array}{l}\text { Feed intake }(\mathrm{g}) \\
(n 8)\end{array}$} \\
\hline & Cys & Met & Mean & SE & Mean & SE \\
\hline $\begin{array}{l}\text { SAA-deficient } \\
\text { SAA-sufficient: }\end{array}$ & 0 & 0 & $742^{b}$ & 29 & $1019^{b}$ & 22 \\
\hline low cysteine & 0 & 3.7 & $892^{2}$ & 18 & $1059^{a}$ & 15 \\
\hline medium cysteine & 1.85 & 1.85 & $862^{\mathrm{a}}$ & 42 & $1076^{\mathrm{a}}$ & 24 \\
\hline high cysteine & 3.7 & 0 & $880^{\mathrm{a}}$ & 16 & $1054^{a}$ & 23 \\
\hline
\end{tabular}

\footnotetext{
a,b Mean values within a column with unlike superscript letters were significantly different, $P<0.05$.

* Initial body weight was 160 (SE 5) g.

$\dagger$ For details of diets and procedures, see pp. 816-817.
} 


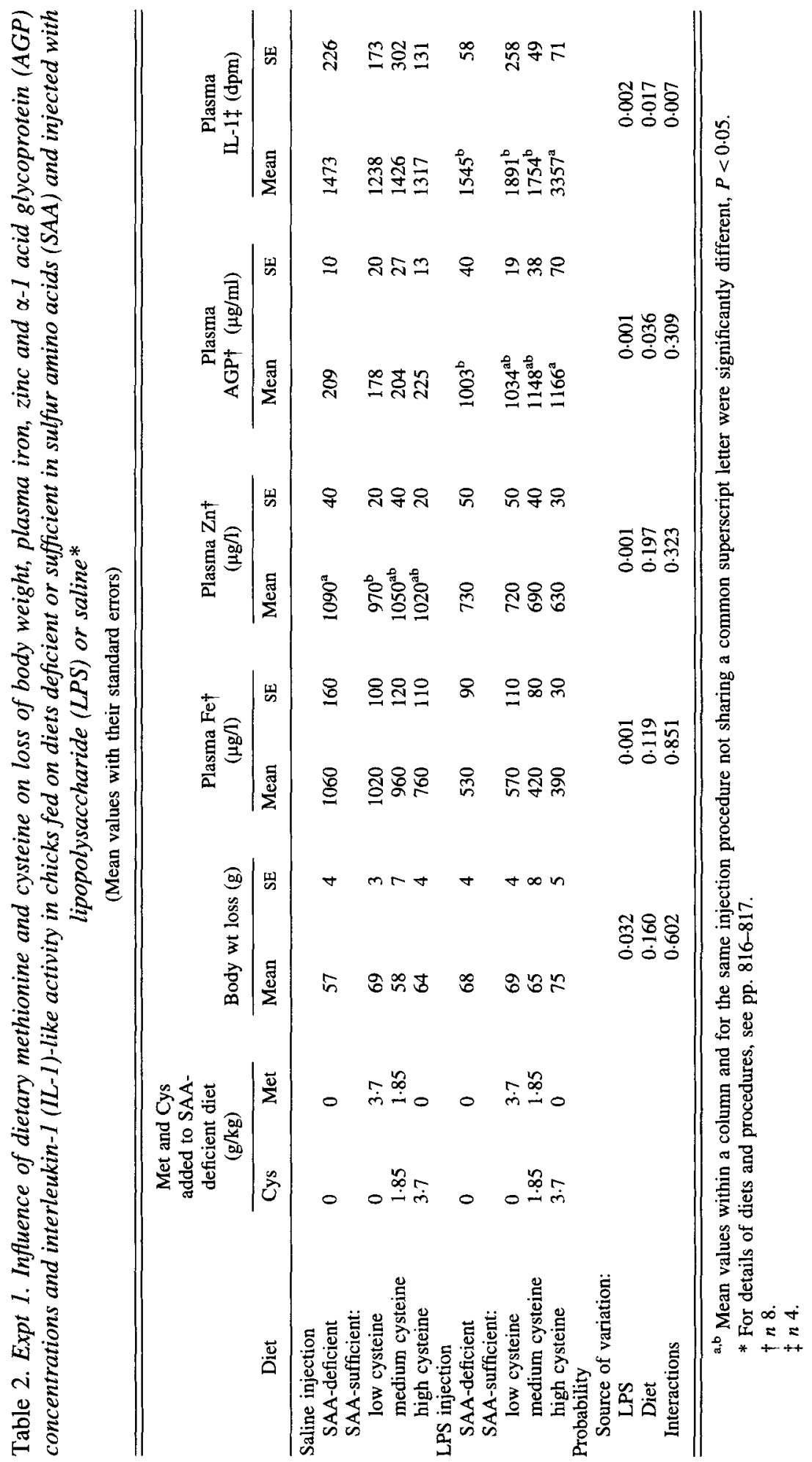


significantly greater in chicks fed on the high-cysteine diet than in chicks fed on the low- or medium-cysteine diet. No significant difference in the Con A-induced proliferative response of thymus MNC was observed between dietary treatments.

\section{DISCUSSION}

It is well known that IL-1, IL- 6 and TNF- $\alpha$ produced by macrophages are important regulators of metabolic responses during the early stages of inflammation. The magnitude of dietary SAA intake has an important bearing on the extent of the metabolic response to TNF in rats (Grimble et al. 1992; Hunter \& Grimble, 1994) and to immune stimulation in chickens (Klasing \& Barnes, 1988). The present results, showing that plasma IL-1-like activity is enhanced by dietary SAA, are in good agreement with previous observations in rats (Grimble et al. 1992; Hunter \& Grimble, 1994) and chickens (Klasing \& Barnes, 1988). Severe trauma and infection bring about a number of major changes in plasma amino acids including methionine and cysteine. SAA might be required in increased amounts for synthesis of acute phase proteins which are concerned with defence mechanisms against tissue damage and infections (Grimble, 1992). AGP is also a positive acute phase protein in chicks (Takahashi et al. 1994). This explanation also seems appropriate for the present results since the degree of response of AGP concentration following LPS injection was higher in chicks fed on the SAA-sufficient diet as compared with chicks fed on the SAA-deficient diet. Thus, a deficient supply of SAA appears to result in a reduced acute response to LPS.

The present experiment showed that plasma IL-1 like activity following LPS injection and $\mathrm{T}$ cell activity of the spleen estimated by Con A-induced MNC proliferation were greater in chicks fed on the high-cysteine diet than in chicks fed on the low- or mediumcysteine diet, even though the diets contained $9.3 \mathrm{~g} \mathrm{SAA} / \mathrm{kg}$ diet which is recommended by the National Research Council (1984) feeding standard. Tsiagbe et al. (1987a) showed that cysteine was $70-84 \%$ as efficient as methionine in enhancing IgG production and in delaying hypersensitivity to PHA-P stimulation. Thus dietary cysteine is not only important for T-cell function and antibody production, but also for macrophage response to LPS in broilers. However, our previous study (Takahashi et al. 1995) showed that a low-protein diet enhanced plasma IL-1-like activity compared with a high-protein diet in chicks, even though the supply of SAA from the diet in chicks fed on a low-protein diet was much less than that in chicks fed on a high-protein diet. These observations suggest that supply of SAA may not be the only factor affecting the immune responses. The combined results of the previous (Takahashi et al. 1995) and the present experiments, suggest that, as well as the supply of SAA, the methionine:cysteine ratio in the diet is an important factor affecting some immune responses, e.g. IL-1-like activity, AGP concentration in plasma and mitogenic response of MNC in spleen. The present results also suggest that dietary cysteine intake has an impact on the immune and inflammatory responses, although replacement of cysteine with methionine in diets would not impair growth and reproduction within certain ratios in the diet (Graber \& Baker, 1971; Ohta \& Ishibashi, 1994 and the present study).

Cysteine plays crucial roles in detoxification and in protecting cells from the action of reactive $O$ species and free radicals as a component of GSH (Boebel \& Baker, 1983; Enkvetechakul \& Bottje, 1995). Proliferative responses of mitogenically stimulated lymphocytes are enhanced by increases in extracelluar cysteine, suggesting that cysteine supply is limiting for certain lymphocyte functions (Franklin et al. 1990; Zmuda \& Friedenson, 1983). In addition, macrophages consume cystine and release approximately equivalent amounts of cysteine (Droge et al. 1991). Stimulation of macrophages with 


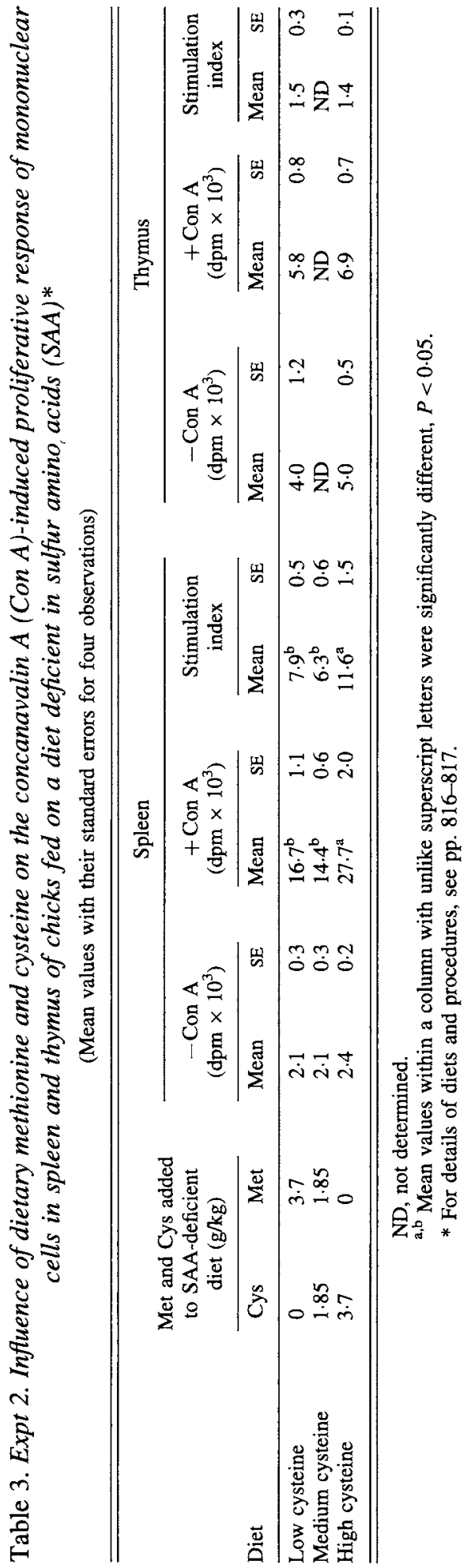


bacterial LPS or TNF strongly augments release of cytokines by these cells (Droge et al. 1991). Further studies need to investigate whether the results of the present experiment (i.e. that dietary cysteine enhances the Con A-induced proliferative response of spleen MNC and plasma IL-1 activity in plasma) could be explained by the concepts obtained by the in vitro studies mentioned earlier.

\section{REFERENCES}

Boebel, K. P. \& Baker, D. H. (1983). Blood and liver concentrations of glutathione and plasma concentrations of sulfur-containing amino acids in chicks fed deficient, adequate, or excess levels of dietary cysteine. Proceedings of the Society for Experimental Biology and Medicine 172, 498-501.

Droge, W., Eck, H. P., Gmunder, H. \& Mihm, S. (1991). Modulation of lymphocyte functions and immune responses by cysteine and cysteine derivatives. American Journal of Medicine 30, 104S-114S.

Enkvetechakul, B. \& Bottje, W. G. (1995). Influence of diethylmaleate and cysteine on tissue glutathione and growth in broiler chickens. Poultry Science 74, 864-873.

Franklin, R. A., Li, Y. I., Arkins, S. \& Kelley, K. W. (1990). Glutathione augments in vitro proliferative responses of lymphocytes to concanavalin A to a greater degree in old than in young rats. Journal of Nutrition 120, 1710-1717.

Graber, G. \& Baker, D. H. (1971). Sulfur amino acid nutrition of the growing chick: quantitative aspects concentrating the efficiency of dietary methionine. Journal of Animal Science 33, 1005-1011.

Grimble, R. F. (1992). Dietary manipulation of the inflammatory response. Proceedings of the Nutrition Society 51, 285-294.

Grimble, R. F., Jackson, A. A., Persaud, C., Wride, M. J., Delers, F. \& Engler, R. (1992). Cysteine and glycine supplementation modulate the metabolic response to tumor necrosis factor alpha in rats fed a low protein diet. Journal of Nutrition 122, 2066-2073.

Hunter, E. A. L. \& Grimble, R. F. (1994). Cysteine and methionine supplementation modulate the effect of tumor necrosis factor alpha on protein synthesis, glutathione and zinc concentration of liver and lung in rats fed a low protein diet. Journal of Nutrition 124, 2319-2338.

Klasing, K. C. \& Barnes, D. M. (1988). Decreased amino acid requirements of growing chicks due to immunological stress. Journal of Nutrition 118, 1158-1164.

National Research Council (1984). Nutrient Requirements of Poultry, 8th revised ed., pp. 35-47. Washington, DC: National Academic Press.

Nauss, K. M., Connor, A. M., Kacancaugh, A. \& Newbern, P. N. (1982). Alteration in immune function in rats caused by dietary lipotrope deficiency: effect of age. Journal of Nutrition 112, 2333-2341.

Ohta, Y. \& Ishibashi, I. (1994). Dietary levels and ratio of methionine and cystine for maximum performance of broilers. Japanese Poultry Science 31, 369-380.

Takahashi, K. \& Akiba, Y. (1996). Effect of dietary corticosterone on mononuclear cells proliferation to mitogen in spleen and thymus of broiler chicks. Animal Science and Technology (Japan) 67, 160-164.

Takahashi, K., Kaji, S., Akiba, Y. \& Tamura, K. (1994). Plasma alpha 1 acid glycoprotein concentration in broilers: influence of age, sex and Escherichia coli lipopolysaccharide. British Poultry Science 35, 427-432.

Takahashi, K., Yodogawa, S., Akiba, Y. \& Tamura, K. (1995). Effect of dietary protein concentration on responses to Escherichia coli endotoxin in broiler chickens. British Journal of Nutrition 74, 173-182.

Tsiagbe, V. K., Cook, M. E., Harper, A. E. \& Sunde, M. L. (1987a). Efficiency of cysteine in replacing methionine in the immune responses of broiler chicks. Poultry Science 66, 1138-1146.

Tsiagbe, V. K., Cook, M. E., Harper, A. E. \& Sunde, M. L. (1987b). Enhanced immune responses in broiler chicks fed methionine supplemented diets. Poultry Science 58, 1147-1154.

Zmuda, J. \& Friedenson, B. (1983). Changes in intracellular glutathione levels in stimulated and unstimulated lymphocytes in the presence of 2-mercaptoethanol or cysteine. Journal of Immunology 130, 362-364. 